\title{
Magnetic Fixed-bed Column for Cr(VI) Removal from Aqueous Solution Using Schwertmannite
}

\author{
Akbar ESKANDARPOUR, ${ }^{1)}$ Maurice S. ONYANGO, ${ }^{2)}$ Mitsuru TANAHASHI, ${ }^{1)}$ Aoyi OCHIENG, ${ }^{31}$ \\ Yoshiyuki BANDO, ${ }^{1)}$ Kazuhiko IWAI, ${ }^{1)}$ Masazumi OKIDO") and Shigeo ASAI ${ }^{1)}$ \\ 1) Graduate School of Engineering, Nagoya University, Nagoya 464-8603 Japan. E-mail: h052103d@mbox.nagoya-u.ac.jp, \\ mtana@numse.nagoya-u.ac.jp, bando@nuce.nagoya-u.ac.jp, d42859a@cc.nagoya-u.ac.jp, okido@numse.nagoya-u.ac.jp, \\ asai@tokai.jst-plaza.jp \\ 2) Department of Chemical and Metallurgical Engineering, Tshwane University of Technology, \\ Pretoria 0001-South Africa. \\ E-mail: onyi72uk@yahoo.co.uk $\quad 3)$ School of Chemical and Metallurgical Engineering, \\ University of Witwatersrand, Bag 3 Wits 2050, South Africa. E-mail: aoyio@yahoo.com
}

(Received on October 1, 2007; accepted on December 5, 2007)

\begin{abstract}
The fine particles of schwertmannite as an iron oxyhydroxide adsorbent has been suggested as a novel and strong $\mathrm{Cr}(\mathrm{VI})$ sorbent for treatment of $\mathrm{Cr}$-contaminated industrial wastewater. The removal process was conducted in both batch and continuous trials. As a result of the batch experiments, the maximal adsorption capacity of the schwertmannite was obtained as $178 \mathrm{mg} / \mathrm{g}$ which was quite high amount in comparison with the usual applied $\mathrm{Cr}(\mathrm{VI})$ sorbents in the literatures. The continuous removal process involved a combination of a fixed bed column with a high gradient magnetic field which was firstly introduced as a novel designation of a fixed bed column to overcome the difficulties accompanied with the application of some especial fine particle adsorbents through the fixed-beds. The experimental results revealed that the magnetization force had a great function in this process to control the shape and the fitness of the bed during the sorption test as well as to simplify the experimental set-up.
\end{abstract}

KEY WORDS: magnetic fixed bed column; Cr removal; high magnetic field; schwertmannite; wastewater treatment; electromagnetic processing of materials.

\section{Introduction}

Widespread usage of chromium in a variety of industrial applications like electroplating, leather tanning, metallurgical processing of ferrochromium, etc., has encouraged an accelerating progress in environmental researches for controlling $\mathrm{Cr}$ ions concentration in industrial discharging waters and trying to develop new technologies for $\mathrm{Cr}$ removal from its solutions. A plenty of relevant research works have been carried out very recently ${ }^{1-7)}$ emphasizing a great environmental concern about this issue. Chromium exists in two oxidation states as $\mathrm{Cr}(\mathrm{III})$ and $\mathrm{Cr}(\mathrm{VI})$. The most toxic state of chromium is $\mathrm{Cr}(\mathrm{VI})$ which has been reported to be 500 times more toxic than the trivalent. ${ }^{8)}$ A verity of methods can be utilized to remove chromium including chemical precipitation, ion exchange, adsorption, solvent extraction, membrane separation, reverse osmosis and bio-sorption. ${ }^{9)}$ Among them, precipitation, adsorption and ion exchange are the most well known methods for $\mathrm{Cr}$ removal. Although precipitation, usually by using of lime, is utilized for chemical precipitation and separation of $\mathrm{Cr}$ (III), but this method can not be used for $\mathrm{Cr}(\mathrm{VI})$ since it doesn't precipitate in any form. ${ }^{10)}$ That is, $\mathrm{Cr}(\mathrm{VI})$ must be reduced to $\mathrm{Cr}(\mathrm{III})$ before precipitation. Considering the problems related to the colloidal states of suspended liquids to reach to the desired ef- fluent neutralization states, and also the possibility of formation of complex ions dealing with solutions containing heavy metals, ${ }^{11)}$ the control of the chemical precipitation system is not so easy. Therefore, chemical adsorption can be considered as one of the most effective methods for $\mathrm{Cr}(\mathrm{VI})$ removal from aqueous solutions, especially if combined with appropriate regeneration steps. Several approaches by introducing low-cost and effective adsorbents have been reported during the last few years.

Iron oxides (hydroxides) have gained a lot of interest to be used as novel and strong chemical adsorbents and catalyst during the last decade due to their abundance and unique surface catalytic properties as well as the new developments on their synthesis especially in nano-size scales which denote some unique physical and chemical properties to them. ${ }^{12)}$ In our pervious studies, we have illustrated that schwertmannite as an iron oxyhydroxide material with the ideal formula of $\mathrm{Fe}_{8} \mathrm{O}_{8}(\mathrm{OH})_{6} \mathrm{SO}_{4}$ has a quite high adsorption capacity of phosphate and fluoride ions with a high regeneration capability in a simple method. Its extremely fine particle size, however, makes it difficult to be applied along with the classical filtration techniques for solid-liquid separation. Thus, magnetic filtration can be considered as a suitable candidate for separation of fine schwertmannite particles from its suspended liquid. ${ }^{13)}$ Magnetic filtra- 
tion, however, has some inherent limitations to be utilized as a continuous filtering system because of time-dependent plugging and saturation of its matrix.

The most optimal configuration for continuous-flow sorption is the packed-bed column which gets gradually saturated from the feed to the solution exit end. High-quality fixed-bed column hardware is the subject of several US patents. In our study work, the experimental trials of the process have been conducted for many times by directly packing the column with the fine particle size of schwertmannite as the most strong $\mathrm{Cr}$ adsorbents. Extremely fine particles and mud like properties of the adsorbent, however, has caused a verity of problems to the system such as high pressure drop, mass transfer resistance and so on. To solve the problems dealing with the system, a magnetic fixed-bed column, as a novel designation of the fixed-bed columns, has been presented in this study. Moreover, the batch $\mathrm{Cr}(\mathrm{VI})$ adsorption data containing equilibrium models using the schwertmannite adsorbent and also the effect of $\mathrm{pH}$ on the adsorption to predict the sorption characteristics of the adsorbent have been given.

\section{Materials and Methods}

All chemicals used were of high purity and analytical grades. The schwertmannite powder as the chemical adsorbent of $\mathrm{Cr}(\mathrm{VI})$ in these experiments was made by homogenous hydrolysis of iron ferric salt $\left(\mathrm{Fe}_{2}\left(\mathrm{SO}_{4}\right)_{3} \cdot n \mathrm{H}_{2} \mathrm{O}\right)$ according to the methods mentioned in our pervious work. ${ }^{14)}$ Stock solution of $130 \mathrm{mg} / \mathrm{L}$ of $\mathrm{Cr}(\mathrm{VI})$ for use in the fixed column experiment was prepared by dissolving of a known amount of $\mathrm{K}_{2} \mathrm{Cr}_{2} \mathrm{O}_{7}$ in dionized water. In the batch mode adsorption trials, $50 \mathrm{~mL}$ of the solution with desired concentrations of $\mathrm{Cr}$ and the adsorbent were mixed in a bottle of $100 \mathrm{~mL}$ and shaken for about $5 \mathrm{~h}$ to reach to the equilibrium state. Then the yielded solution was filtered through a paper filter and then chromium concentration in filtrate was analyzed to assess the adsorption behavior of $\mathrm{Cr}(\mathrm{VI})$ on the adsorbent. Diluted $\mathrm{HCl}$ and $\mathrm{NaCl}$ were used to adjust the $\mathrm{pH}$ values of the solution samples containing $\mathrm{Cr}$ ions and the schwertmannite.

$\mathrm{Cr}$ concentration was measured by using an inductively coupled plasma atomic emission spectroscopy (ICP). The particle size distribution and the mean size of the schwertmannite particles were determined using a laser scattering particle size distribution analyzer (LA-920). The specific surface area of schwertmannite particles was measured using BET analysis.

\section{Adsorption Equilibrium}

Adsorption isotherm study was conducted at solution $\mathrm{pH}$ 4.2 and is presented in the form of equilibrium uptake against equilibrium concentration. Equilibrium data are important in evaluating the adsorption capacity of an adsorbent for a given adsorbate. Information derived from such data is important also in comparing different adsorption media and for coupling the data into kinetic models. In Fig. $\mathbf{1}$, it is shown that schwertmannite is amphoteric in nature. This is a common phenomenon with iron based adsorbents, which has also been reported by Wang and Reardon ${ }^{15)}$ and

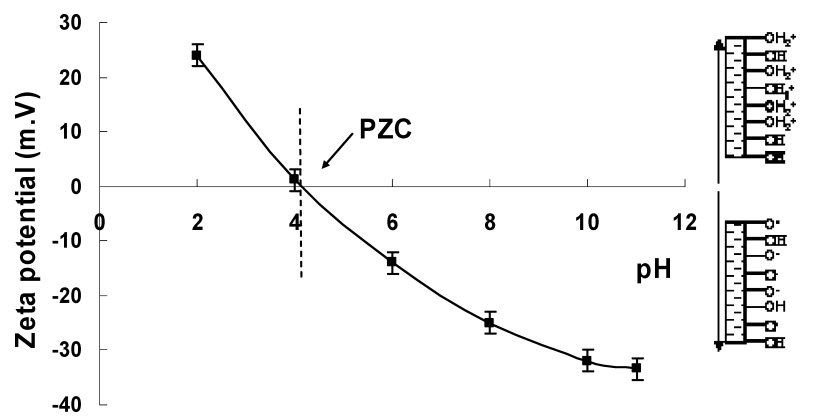

Fig. 1. Zeta potential measurement of the schwertmannite sample.

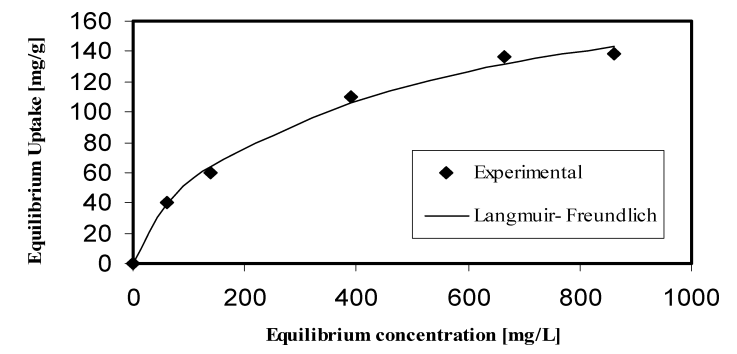

Fig. 2. Adsorption equilibrium isotherm for $\mathrm{Cr}(\mathrm{VI})$ uptake by schwertmannite.

Hiemstra and van Riemsdijk. ${ }^{16)}$ At low $\mathrm{pH}$, the active sites, being positively charged, have a strong binding power for anionic ligands through the formation of inner sphere complexes. In this section, $\mathrm{Cr}(\mathrm{VI})$ adsorption results at $\mathrm{pH} 4.2$ are presented in the form of equilibrium isotherms as shown in Fig. 2. If at $\mathrm{pH} \mathrm{4.2,} \mathrm{the} \mathrm{effective} \mathrm{active} \mathrm{sites} \mathrm{are}$ assumed to consist of neutral sites $\left(\mathrm{pH}_{\mathrm{pzc}}\right.$ of schwertmannite $\approx 4.2$ ), which are distributed uniformly, then it is justifiable to describe the equilibrium data with the Langmuir isotherm. Alternatively, the equilibrium data can be mathematically described by Freundlich, Langmuir-Freundlich and Redlich-Peterson isotherms. These isotherms are summarized in Table 1.

The equilibrium data of $\mathrm{Cr}(\mathrm{VI})$ adsorption on to schwertmannite were fitted to the linearized Langmuir isotherm (see Eq. (1) for non-linear form). Judging from the high values of $R^{2}$, the Langmuir isotherm gives a satisfactory fit to the experimental data set. From the linear plots (not shown), the Langmuir isotherm parameters were determined and are summarized in Table 2. The maximum capacity, $q_{\mathrm{m}}$, is $178.6 \mathrm{mg} / \mathrm{g}$ and the affinity coefficient, $b$, is $0.0042 \mathrm{~L} / \mathrm{mg}$. Recently, several researchers have studied the adsorption of $\mathrm{Cr}(\mathrm{VI})$ and interpreted their equilibrium results using the Langmuir isotherm. For instance, Malkoc and Nuhoglu ${ }^{17)}$ have used tea factory waste to remove $\mathrm{Cr}(\mathrm{VI})$ from the aqueous solution and found the Langmuir maximum adsorption capacity of $54.65 \mathrm{mg} \mathrm{g}^{-1}$. Gasser et $a l{ }^{18)}$ used various synthetic adsorbents and found the $\mathrm{Cr}$ (VI) capacity of the adsorbents to vary in the range $18.8-22.4 \mathrm{mg} / \mathrm{g}$. Using amorphous alumina oxide to remove $\mathrm{Cr}(\mathrm{VI})$ from electroplating wastewater, Álvarez-Ayuso et $a l .{ }^{19)}$ found the Langmuir capacity depended on ionic strength but generally varied in the range $63.1-78.1 \mathrm{mg} / \mathrm{g}$. From several other data published in literature, it is observed that the capacity of schwertmannite for $\mathrm{Cr}(\mathrm{VI})$ is competitively higher than those of other adsorbents. Mean- 
Table 1. Isothermal results.

\begin{tabular}{|c|c|c|}
\hline Isotherm & Equation & Eq. no. \\
\hline Langmuir & $q_{e}=\frac{q_{m} b C_{e}}{1+b C_{e}}$ & (1) \\
\hline Freundlich & $q_{e}=K_{F} C_{e}^{1 / n}$ & (2) \\
\hline Langmuir-Freundlich & $q_{e}=\frac{K_{L F} C_{e}^{1 / n}}{1+a_{L F} C_{e}^{1 / n}}$ & (3) \\
\hline Redlich-Peterson & $q_{e}=\frac{K_{R P} C_{e}}{1+a_{R P} C_{e}^{1 / n}}$ & (4) \\
\hline
\end{tabular}

Table 2. Summary of equilibrium isotherm parameters.

\begin{tabular}{|c|c|c|c|c|c|c|}
\hline \multirow[t]{2}{*}{ Isotherms } & \multicolumn{6}{|c|}{ Parameters } \\
\hline & $q_{\mathrm{m}}$ & $b$ & $K_{F}, K_{\mathrm{RP}}, K_{\mathrm{LF}}$ & $a_{\mathrm{RP}, \mathrm{RF}}$ & $1 / n$ & $R^{2}$ \\
\hline Langmuir & 178.6 & 0.0042 & - & - & - & 0.992 \\
\hline Freundlich & & & 5.40 & - & 0.49 & 0.988 \\
\hline Redlich- & & & 5.40 & 0.755 & 0.55 & 0.990 \\
\hline \multicolumn{7}{|l|}{ Peterson } \\
\hline Langmuir- & & & 2.35 & 0.0089 & 0.725 & 0.991 \\
\hline Freundlich & & & & & & \\
\hline
\end{tabular}

while, the Freundlich isotherm was also tested in the nonlinear form presented in Eq. (2). A fairly good fit was obtained with regression coefficient, $R^{2}=0.988$. The Freundlich parameters are summarized in Table 2 . The value of the parameter associated with adsorption capacity is 5.40 while the heterogeneity coefficient is 0.49 . The fitting validity of three-parameter models, Redlich-Peterson and Langmuir-Freundlich (Sips isotherm), was tested in the linearized forms (see Eqs. (3) and (4) for non-linear forms) according to a simple procedure described by Onyango et $a{ }^{20)}$ For the Redlich-Peterson model, the parameters $a_{\mathrm{RP}}$ and $1 / n$ were determined from the intercepts (extrapolated to $\ln C_{\mathrm{e}}=0$ ) and slopes of the linear curves while by maximizing the regression coefficient, $K_{\mathrm{RP}}$ was obtained. The parameters $K_{\mathrm{RP}}, a_{\mathrm{RP}}$, and $1 / n$ were $5.4,0.755$, and 0.55 , respectively. Similarly, the Langmuir-Freundlich isotherm parameters were obtained in a similar fashion to those of Redlich-Petersen model, and are $2.35\left(K_{\mathrm{LF}}\right), 0.0089\left(a_{\mathrm{LF}}\right)$ and $0.725(1 / n)$.

\section{Effect of pH}

The $\mathrm{pH}$ of an aqueous solution controls the speciation of an adsorbate and the nature of the active sites. When an adsorption system is operated at $\mathrm{pH}$ below the $\mathrm{pH}_{\mathrm{pzc}}$ of an ad- sorption media, an electrostatic attraction between the active sites on the adsorption media and the negatively charged adsorbate ions is expected to enhance the removal of the adsorbate from solution. At $\mathrm{pH}$ values above the $\mathrm{pH}_{\mathrm{pzc}}$ of an adsorption media, repulsive forces play a role in uptake. In this study, the solution $\mathrm{pH}$ was varied from 0.5 to 6.5. Chromium(VI) in the preceding $\mathrm{pH}$ range exists as oxyanion $\mathrm{HCrO}_{4}{ }^{-}$, while the active sites on schwertmannite are either positive (when $\mathrm{pH}<\mathrm{pH}_{\mathrm{pzc}}$ ) or negative (when $\left.\mathrm{pH}>\mathrm{pH}_{\mathrm{pzc}}\right)$. Figure 3 below shows the uptake of $\mathrm{Cr}(\mathrm{VI})$ at various $\mathrm{pH}$ values. The uptake values of $\mathrm{Cr}(\mathrm{VI})$ ions are high, but there is a decrease in the uptake value with an increase in $\mathrm{pH}$. The latter phenomenon is widely reported in literatures (Arslan and Pehlivan ${ }^{1)}$; $\mathrm{Hu}$ et al. ${ }^{4}$; Malkoc and Nuhoglu ${ }^{17)}$ ). It results from the fact that as $\mathrm{pH}$ is increased the activity of the active sites is suppressed and in fact at $\mathrm{pH}$ values above the $\mathrm{pH}_{\mathrm{pzc}}$, electrostatic repulsive forces further suppress the interaction between $\mathrm{Cr}$ (VI) (in the form $\mathrm{HCrO}_{4}^{-}$) and the active sites. Although the Cr-uptake decreases in all cases with increase in $\mathrm{pH}$, there is a small discontinuity as a sudden drop in uptake at the $\mathrm{pH}$ of about 4 . Since coulombic attraction plays a significant role in $\mathrm{Cr}$ uptake, it could explain such a point of discontinuity in uptake at the portion with the change from protonated particles (the $\mathrm{pH}$ of point of zero charge is about 4-4.2) to neutral 
particles. Because significant removal of $\mathrm{Cr}(\mathrm{VI})$ specie is observed at $\mathrm{pH}$ values where schwertmannite is negatively charged, it can be concluded that chemical interaction dominates $\mathrm{Cr}(\mathrm{VI})$ adsorption in the present system.

\section{Magnetic Fixed-bed Column}

Fixed bed column is the most common method used in industrial application of chemical adsorbents wherein convection along the column axial direction and axial dispersion are the mass transport mechanisms in the bulk phase. Intraparticle diffusion is usually the rate-limiting step in these systems and it controls the sharpness of breakthrough curves. Figure 4 represents a typical breakthrough curve of a fixed-bed column wherein the function of $f(t)$ is the effluent curve and the estimated area of the shadow part is representing the overall amount of ions adsorbed by the column which is obtained from the following equation;

$$
q=\frac{\left(t_{\mathrm{e}}-\int_{t_{\mathrm{b}}}^{t_{\mathrm{e}}} f_{(t)} d t\right) Q C_{0}}{W}
$$

where $q$ is the amount of ions adsorbed per unit weight of the adsorbent, $Q, C_{0}, C$ and $W$ represent volumetric flow rate $(\mathrm{mL} / \mathrm{min})$, influent and effluent concentration $(\mathrm{mg} / \mathrm{mL})$, and dry weight of adsorbent applied $(\mathrm{g})$, respectively. $t_{\mathrm{b}}$ and $t_{\mathrm{e}}$ are time to breakthrough ( $\left.\mathrm{min}\right)$, and time at exhaustion (min), respectively. Operation of the column was stopped when the ratio of effluent-to-influent concentration exceeded a value of $0.9 .^{21}$ )

Fine particle size and large specific surface area of the

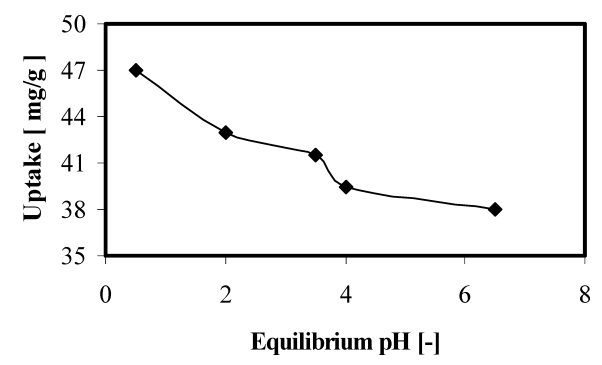

Fig. 3. Effect of $\mathrm{pH}$ on $\mathrm{Cr}(\mathrm{VI})$ removal from aqueous solution by schwertmannite. Adsorbent dose $1 \mathrm{~g} / \mathrm{L}$, initial concentration $=100 \mathrm{mg} / \mathrm{L}$, temperature $=22^{\circ} \mathrm{C}$, equilibrium time $=$ $6 \mathrm{~h}$. adsorbent, however, increases pressure drop and plug flow along the column. In our case, the measured particle size of schwertmannite ranged from 0.3 to several $\mu \mathrm{m}$ with the average particle size of $8 \mu \mathrm{m}$ and the measured specific surface area of $165 \mathrm{~m}^{2} / \mathrm{g}$ give a specific colloidal property to this material which remarkably increases flow-transfer resistance through the bed due to its mud-like characteristic. To overcome these limitations associated with the process and avoid clogging the column, the application of multilayer packed bed is inevitable. A novel packed column type is firstly introduced here namely "Magnetic Fixed Bed Column" which jointly works with a high gradient magnetic field to simplify the system and improve the main characters of the fixed-beds.

In this designation, ferromagnetic wools or wires as high porous media are alternately inserted into the column which is loaded by the adsorbent as the relatively same height as wools. Figure 5 exhibits a small-scale physical model of the suggested process wherein schwertmannite powder was packed in a glass-made column with $2 \mathrm{~cm}$ diameter in a manner so that ferromagnetic wool-layers might be alternately laid among the adsorbent layers. In each layer of the adsorbent and porous media, $1 \mathrm{~g}$ schwertmannite and $0.4 \mathrm{~g}$ iron wools were packed, respectively. The overall height of the bed depth was $5 \mathrm{~cm}$. After packing them in the column, the column was located in the middle of the highest gradient of a high magnetic field with $4 \mathrm{~T}$ of magnetic intensity. The prepared stock solution containing $\mathrm{Cr}(\mathrm{VI})$ was then passed through the fixed-bed column located in the high magnetic field in an upward model using a peristaltic pump. The effluent samples were collected at a certain time interval and analyzed for $\mathrm{Cr}$ concentration remaining.

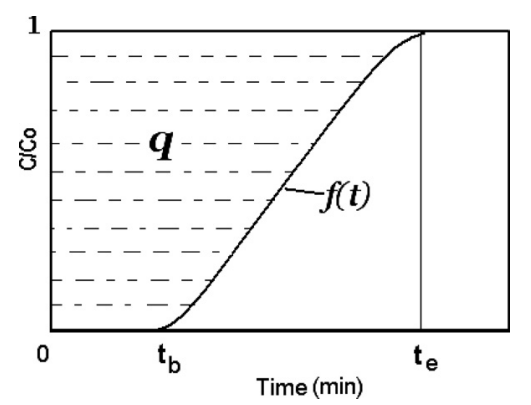

Fig. 4. A typical breakthrough of fixed bed column.

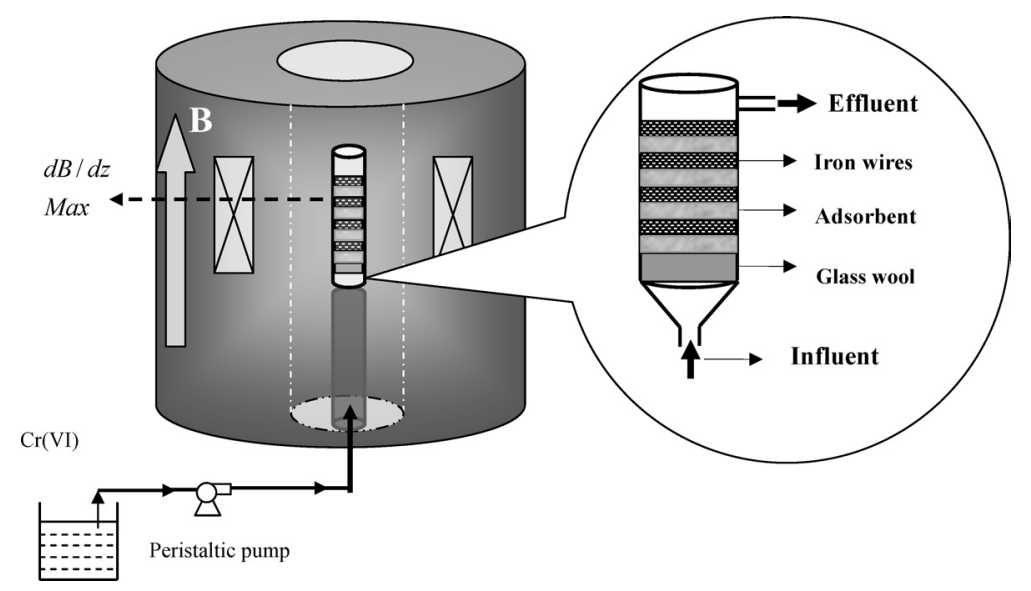

Fig. 5. A schematic view of the magnetic fixed bed column in this study. 


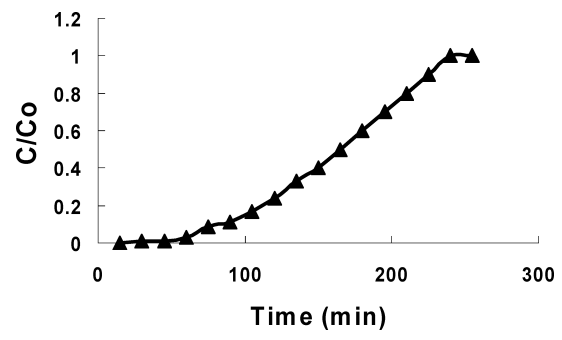

Fig. 6. Breakthrough curve of the magnetic fixed bed column in this study.

\section{Results and Discussion}

The imposed high magnetic field in this process has a great role to retain the shape and the fitness of the column bed during the feeding of the bed. In fact, the magnetization force acts as a holding force to maintain the bed's condition to be constant. That is, as a result of the strongly keeping the ferromagnetic wires to the column's wall by the magnetization force without requiring to any foreign forces, we have a simplicity in the hardware of the fixed bed comparing to the usual fixed beds. Figure 6 represents the breakthrough curve of the magnetic fixed bed as an assessment of the process. According to the obtained results, the breakthrough curve of the process is thoroughly similar to the typical curves of a fixed bed column which confirms the successful operation of this process. For 4-g of the used schwertmannite, the total amount of the $\mathrm{Cr}$ ion adsorbed was computed, from the data obtained from Fig. 2, as $740 \mathrm{mg}$ which is equal to $185 \mathrm{mg} \mathrm{Cr} / \mathrm{g}$ of the schwertmannite. That is, Cr-adsorption in this process was increased comparing to the maximal $\mathrm{Cr}$ adsorption capacity of the schwertmannite obtained in the batch adsorption trials. This may be explained by the nano-effect interaction of iron wool and $\mathrm{Cr}$ ions under the high gradient magnetic field. ${ }^{22)}$

The invariable amounts of the output slurries in each interval indicate that the physical condition of the column bed was unchanged during the process. In addition, the contact time between the loaded slurry and the adsorbent may be increased as a consequence of the magnetic field effect on the flow pattern of the fed slurry into the column bed which may results in an increase on the overall ions adsorbed in the process.

\section{Conclusions}

In this study, magnetic fixed bed column has been intro- duced as a novel designation of a fixed bed column which is loaded by alternately schwertmannite, as an adsorbent, and ferromagnetic wools, as a high porous media, working under high magnetic field as a very efficient media for $\mathrm{Cr}(\mathrm{VI})$ removal from water. Application of a magnetization force in this process not only simplifies the experimental set-up of the fixed bed, but also keeps the bed's condition constant as a significant parameter for bed columns dealing with submicron and nano-particle adsorbents.

\section{Acknowledgements}

This work was partially supported by JSPS Asian Core Program "Construction of the World Center on Electromagnetic Processing of Materials".

\section{REFERENCES}

1) G. Arslan and E. Pehlivan: Bioresour. Technol., 98 (2007), 2836.

2) J. M. Sun, S. Y. Chang, R. Li and J. C. Huang: Sep. Purif. Technol., 56 (2007), 57.

3) F. Di Natale, A. Lancia, A. Molino and D. Musmarra: J. Hazard. Mater, 145 (2007), 381.

4) J. Hu, G. Chen and I. M. C. Lo: Water Res., 39 (2005), 4528.

5) S. H. Hasan, K. K. Singh, O. Prakash, M. Talat and Y. S. Ho: J. Hazard. Mater, (2007) in press.

6) H. Li, T. Liu, Z. Li and L. Deng: Bioresour. Technol., (2008), in press.

7) F. Venditti, A. Ceglie, G. Palazzo, G. Colafemmina and F. Lopez: J. Coll. Int. Sci., 310 (2007), 353.

8) Z. Kowalski: J. Hazard. Mater., 37 (1994), 137.

9) A. K. Bhattacharya, T. K. Naiya, S. N. Mondal and S. K. Das: Chem. Eng. J., (2008), in press.

10) C. Peng, H. Meng, S. Song, S. Lu and A. L. Valdivieso: Sep. Sci. Technol., 39 (2004), 1501.

11) V. Sarin and K. K. Pant: Bioresour. Technol., 97 (2006), 15.

12) A. K. Gupta and M. Gupta: Biomaterials, 26 (2005), 3995.

13) A. Eskandarpour, K. Sassa, Y. Bando, M. Okido and S. Asai: Mater. Trans., 47 (2006), 1832.

14) A. Eskandarpour, K. Sassa, Y. Bando, M. Okido and S. Asai: ISIJ Int., 47 (2007), 563.

15) Y. Wang and E. J. Reardon: Appl. Geochem., 16 (2001), 531.

16) T. Hiemstra and W. H. Van Riemsdijk: J. Coll. Int. Sci., 225 (2000), 94.

17) E. Malkoc and Y. Nuhoglu: Chem. Eng. Sci., 61 (2006), 4363.

18) M. S. Gasser, G. A. Morad and H. F. Aly: J. Hazard. Mater, 142 (2007), 118

19) E. Á. Ayuso, A. G. Sánchez and X. Querol: J. Hazard. Mater., 142 (2007), 191.

20) M. S. Onyango, Y. Kojima, O. Aoyi, E. C. Bernardo and H. Matsuda: J. Coll. Int. Sci., 279 (2004), 341.

21) D. Zhou, L. Zhang, J. Zhou and S. Guo: J. Appl. Polym. Sci., 94 (2004), 684.

22) A. D. Ebner, J. A. Ritter, H. J. Ploehn, R. L. Kochen and J. D. Navrtil: Sep. Sci. Technol., 34 (1999), 1277. 